\title{
An improved model of intraspecific aggression: Dose-response analysis of apomorphine-induced fighting and stereotypy in the rat
}

\author{
WILLIAM G. DREW and SARAH E. DeROSSETT \\ University of Kentucky College of Medicine, Lexington, Kentucky 40536 \\ and \\ JAMES E. GOTSICK \\ Morehead State University, Morehead, Kentucky 40351

\begin{abstract}
A paradigm more sensitive and specific than the original apomorphine model proposed by Senault was employed to measure intraspecific aggression in the rat. Several behavioral measures provided detailed descriptions of aggressive and nonaggressive behaviors. Several new aggressive responses not previously attributed to apomorphine were noted. Graded doses of apomorphine were administered to determine the qualitative and quantitative dose-response relationships produced by apomorphine on both aggressive and nonaggressive behaviors. Maximum fighting times were obtained at apomorphine doses of 2.5 and $5.0 \mathrm{mg} / \mathrm{kg}$.
\end{abstract}

Apomorphine-induced aggression is promising as a model for the study of severe intraspecific aggression in rats (McKenzie, 1971; Senault, 1970, 1971, 1972, 1973, 1974). Systematic studies by Senault have revealed that apomorphine-induced aggression in the rat is influenced by age, sex, strain, cage size, and whether one or both members of the fighting pair were injected (Senault, 1970). Senault distinguished three populations of rats exhibiting discrete aggressive responses following intravenous apomorphine administration: (1) nonfighters (62\%), (2) moderate fighters (22\%), fighting time less than $30 \mathrm{~min} / \mathrm{h}$, and (3) high fighters $(16 \%)$, averaging $30 \mathrm{~min}$ of fighting per hour (Senault, 1973).

Subsequently, Senault (1971) studied the effect of isolation, certain limbic and striatal lesions (Senault, 1973), and the role of brain amines on apomorphineinduced aggression (Senault, 1971). His results, however, may have been biased by the use of certain procedures. For example, the only measure of aggression was total fighting time, which gives no information concerning aggressive patterns. Furthermore, the use of a regularly repeated auditory stimulus (bell ringing) during fighting sessions may have resulted in artificially inflated fighting times. In the studies on brain amines, only those pairs categorized as high fighters were included. These arbitrary procedures, especially the selective use of "high fighters," may have increased the probability of finding a drug-induced reduction in aggression, in view of known rate-dependency phenomena. Finally, the data available on dose-response relationship are unclear, with a wide range of doses and routes of administration being used by different investigators (McKenzie, 1971; Senault, 1970; Thor \& Ghiselli, 1975).

While apomorphine has long been noted for its capacity to induce mild to profound stereotypy in rodents, none of the studies cited here measured apomorphine-induced stereotypy concurrently with aggression.

Thus, the purpose of this investigation was threefold. First, a paradigm was employed that included several different indexes of aggression (Gotsick, Drew, \& Proctor, 1975) measured in the absence of artificially biasing auditory stimuli. Second, behavioral observations of both aggressive and nonaggressive behaviors (e.g., social, stereotypy) were made during the fighting session. Finally, dose-response relationships involved in apomorphine-induced aggression and stereotypy were determined.

\section{METHOD}

\section{Subjects}

Subjects were 84 naive male hooded rats (Blue Spruce) 90-110 days of age, individually housed under standard conditions of temperature $\left(74^{\circ} \mathrm{F}-78^{\circ} \mathrm{F}\right.$ ) and lighting (on 7:00 a.m. until 7:00 p.m.), with free access to food and water.

\begin{abstract}
Apparatus
Fighting arenas consisted of circular wire-mesh cages, $25 \mathrm{~cm}$ in diameter and $30 \mathrm{~cm}$ deep (see Gotsick et al., 1975). Two arenas were housed together in a sound-attenuating chamber, separated by a partition that prevented visual contact and limited auditory contact. An observer, blind to drug conditions, operated a remotely located event recorder that recorded fighting responses. From these records, latency to fight, number of attacks, length of each attack, and cumulative fighting time were calculated.
\end{abstract}

\section{Drugs}

Apomorphine hydrochloride (Lilly) was dissolved in a $.001-\mathrm{N} \mathrm{HCl}(\mathrm{pH} 4.5)$ vehicle and was prepared fresh daily to avoid autooxidation. The drug was injected subcutaneously dorsal to the pelvic girdle at one of the following doses: $0,1.25$, $5.0,10$, and $15 \mathrm{mg} / \mathrm{kg}$. These doses were prepared as the salt of the drug. The effects of vehicle dose volumes $(.2-1.75 \mathrm{ml})$ in previous studies have consistently shown no volume effect. Thus, a volume of vehicle equivalent to the volume of a $5-\mathrm{mg} / \mathrm{kg}$ dose level was used $(.05 \mathrm{ml})$ in the control condition. To examine 
the effects of autooxidation, apomorphine solutions were allowed to sit at room temperature under air for at least $24 \mathrm{~h}$ prior to injections.

\section{Procedure}

Subjects were paired on the basis of body weight and randomly assigned to one of six treatment groups $(N=14$, seven pairs except where noted). Thirty minutes prior to testing, both subjects of each pair received an injection of apomorphine or vehicle. In previous studies, stereotypy usually began within 2 min of injection, whereas fighting behaviors did not emerge until approximately $30 \mathrm{~min}$ after subcutaneous injection. After injection, the animals were individually housed in dark plywood holding cages with wire bottoms. Pairs were then placed into the fighting arenas for a 1-h observation period. An experienced observer recorded the occurrence and duration of fighting responses for the pair. Fighting was defined as either of the following: (1) assuming and/or maintaining a fighting posture, more specifically described as rearing on the hind limbs or using the hind feet to maintain distance from the other member of the pair, opening of the mouth that anticipated actual biting, and interlocking of the vibrissae, which usually accompanied mouth opening; (2) any actual contact of a fighting nature, such as biting or pushing with the paws, a behavior resembling "boxing." All behavior was catalogued, and a complete profile prepared for each pair.

Analyses of variance were performed on all data. To approximate normality, raw scores were transformed according to the formula score $=\log X+1$. Post hoc tests (least-squared differences) were performed to determine differences between groups. To evaluate the validity of the three measures of aggression, Pearson product-moment correlation coefficients were calculated.

\section{RESULTS}

\section{Aggressive Behavior}

Our results confirmed earlier findings that apomorphine induces severe intraspecific aggression in male rats as measured by fighting time. Further corroboration of this finding was provided by additional measures of number of attacks per session and latency to attack. Typically, fights involved rearing, boxing, and biting, with no fatalities (in contrast to McKenzie, 1971). However, deep puncture wounds, cuts, and scratches about the head, mouth, and snout, so severe that some animals had to be sacrificed, were seen after many of the fighting sessions.

In addition to the typical responses seen in fighting sessions, several aggressive behaviors not previously attributed to apomorphine occurred. One response, "wrestling," was characterized by a lunging approach in which the opponent's head or shoulder girdle was pinned to the floor. More frequently, however, another peculiar type of pinning response termed "rumping" (Seward, 1945) was noted. One member of the pair repeatedly attacked by rapidly swinging his pelvic girdle at the other animal, serving to pin the opponent's head or body to the side of the cage. Occasionally, one or both members of a pair were observed to rattle their tails during fights.

Fighting onset was usually quite sudden. Both rats would slowly circle the cage, engaged in stereotyped wire licking or chewing. Suddenly, both would rear, boxing with the forepaws and biting. Usually, during these fights, both animals held their heads at an angle about 45 deg above the horizontal, mouths open, with vibrissae interlocked. Fights normally ended when one member of the pair slowly moved his head to one side, disengaging the vibrissae. The disengaging animal would then drop to the floor, resuming stereotyped behavior. The other animal followed within 1 or 2 sec; no further responses to each other were made until the next attack.

Some attacks appeared to be initiated as the result of a startle response to sensory stimulation. For example, chewing of the wire cage occasionally produced a loud or sudden movement that triggered an attack by the other animal. However, many attacks were initiated when no such stimuli could be discerned by the observer, and sometimes, sudden auditory or visual stimulation failed to result in an attack. The 42 pairs of animals were classified as: (1) high fighters (fight time greater than $15 \mathrm{~min}$ ), which included 13 pairs of apomorphine animals and no controls; (2) low fighters (fight time less than $15 \mathrm{~min}$ but greater than $1 \mathrm{~min}$ ), 11 apomorphine and 1 control; or (3) nonfighters (fight time less than $1 \mathrm{~min}$ ), 11 apomorphine and 6 controls. Thus, 37\% of the apomorphine animals were high fighters, but no controls reached this level. On the other hand, $85 \%$ of the controls were nonfighters, with $31 \%$ of apomorphine pairs classified as such. Table 1 shows this classification.

The relationship between dose and aggression is given in Figure 1. Maximum fighting times were obtained at doses of 2.5 and $5.0 \mathrm{mg} / \mathrm{kg}$. Both lower and higher doses were less effective. Number of attacks per session gives essentially the same relationship. Finally, it can be seen that doses of 2.5 and $5.0 \mathrm{mg} / \mathrm{kg}$ result in the shortest latency to fight. Figure 1 also reveals that autooxidized apomorphine produces greatly diminished responses, indicating loss of pharmacological activity.

Analysis revealed significant differences between the dose level groups on number of attacks $[\mathrm{F}(5,36)=$ 2.92, $\mathrm{p}<.05]$, latency $[\mathrm{F}(5,36)=3.98, \mathrm{p}<.01]$, and fight time $[F(5,36)=4.53, p<.005]$. The post hoc test indicated that 2.5 and $5.0 \mathrm{mg} / \mathrm{kg}$ were the only doses that were significantly different from controls for all three measures. Correlation coefficients indicated a positive relationship between fight time and number of attacks $(r=.75, p<.001)$ and negative relationships between fight time and latency to attack $(r=-.73$, $\mathrm{p}<.0001)$ and number of attacks and latency to attack $(\mathrm{r}=-.79, \mathrm{p}<.0001)$. Thus all measures appear to be correlated.

Table 1

Classification of Rat Pairs According to Extent of Aggression Given Graded Doses of Apomorphine

\begin{tabular}{lcccccc}
\hline \multirow{2}{*}{$\begin{array}{c}\text { Classifi- } \\
\text { cation }\end{array}$} & \multicolumn{6}{c}{ Dose Level (in Milligrams per Kilogram) } \\
\cline { 2 - 7 } & 0 & 1.25 & 2.5 & 5.0 & 10.0 & 15.0 \\
\hline High Fighters & 0 & 2 & 2 & 4 & 2 & 1 \\
Low Fighters & 1 & 1 & 3 & 3 & 2 & 2 \\
Nonfighters & 6 & 4 & 0 & 0 & 3 & 4 \\
\hline
\end{tabular}




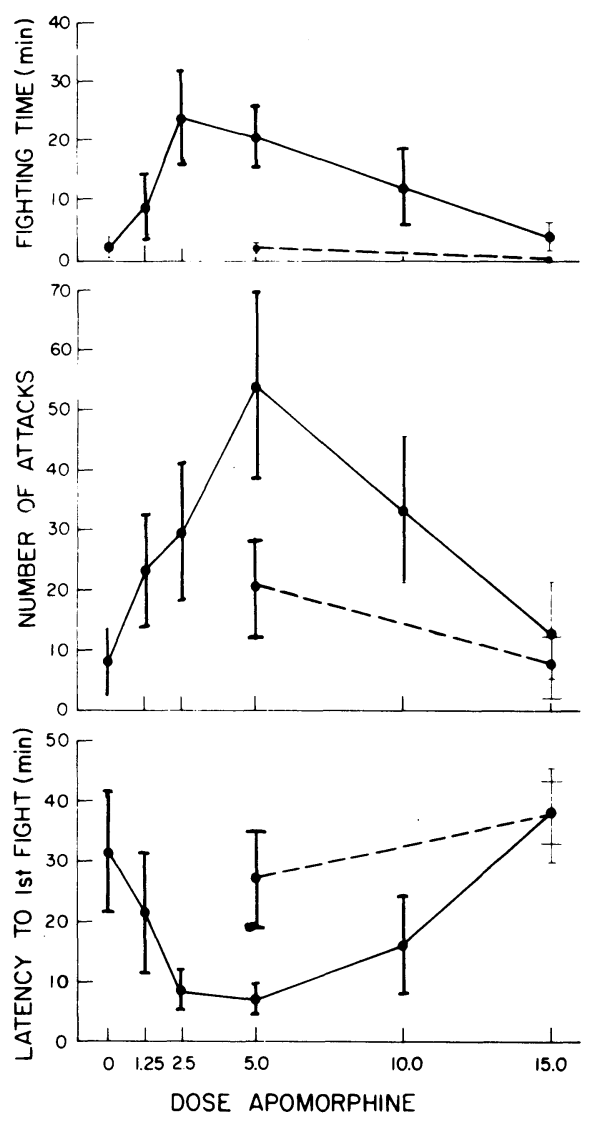

Figure 1. Effect of graded doses of apomorphine (in milligrams per kilogram) (solid lines) on fighting time, mean number of attacks, and fight latency measured on 84 rats over 1-h fighting sessions. The effects of 24-h old apomorphine are denoted by broken lines.

\section{Nonaggressive Behavior}

Typically, stereotypy appeared within 2 min of injection and was well developed upon placement in the fighting arena. Such stereotypy consisted of wire sniffing, licking, or biting while the animal circled the cage floor or climbed the cage walls. Controls responded to sudden auditory or visual stimulation with startle responses, followed by orientation toward the source of the stimulus, accompanied by freezing and sniffing. Apomorphine animals also showed startle responses to sudden sensory stimulation. If an attack did not result, however, they immediately resumed stereotypy, with none of the freezing and sniffing found in controls.

At doses above $5.0 \mathrm{mg} / \mathrm{kg}$, stereotypy became much more intense. Wire biting became so pronounced that occasional injury to the bones and tissue of the snout resulted. As a consequence, several animals pulled out their incisors and two animals suffered broken necks. (These injuries occurred in holding cages either before or after the fighting session. Animals injured prior to fighting were replaced with substitutes.)

Controls showed social interaction with their partners, such as sniffing and grooming. However, after apomorphine, minimal interaction occurred. Apomor- phine rats usually circled the cage, crawling over or under each other. The sniffing and grooming of the partner seen in the controls were conspicuously absent.

A summary of these data is presented in Table 2. This table shows the number of pairs exhibiting each response, but it does not indicate the magnitude of the response or the percent of time spent in such behaviors.

The behavioral profiles induced by graded doses of apomorphine are shown in Figure 2, in which dose levels

Table 2

Summary of Dose-Response Actions of Apomorphine on Fighting and Stereotypy in Paired Adult Hooded Rats

\begin{tabular}{lcccccc}
\hline & \multicolumn{6}{c}{ Dose Level (in Milligrams per Kilogram) } \\
\cline { 2 - 7 } \multicolumn{1}{c}{ Behavior } & 0 & 1.25 & 2.5 & 5.0 & 10.0 & 15.0 \\
\hline Cage Sniffing & 7 & 3 & 1 & 0 & 0 & 0 \\
Grooming & 5 & 4 & 2 & 0 & 0 & 0 \\
Laying Down & 4 & 1 & 0 & 0 & 0 & 0 \\
Stereotypy & 1 & 7 & 7 & 7 & 7 & 7 \\
Rearing & 1 & 1 & 0 & 0 & 2 & 2 \\
Boxing & 1 & 2 & 7 & 7 & 4 & 3 \\
Wrestling & 2 & 0 & 2 & 0 & 0 & 0 \\
Rumping & 2 & 2 & 2 & 0 & 0 & 0 \\
Vocalization & 1 & 4 & 6 & 5 & 4 & 3 \\
Tail Rattling & 0 & 1 & 1 & 0 & 0 & 0 \\
Tail Holding & 0 & 0 & 0 & 0 & 2 & 1 \\
\hline
\end{tabular}

Note-There were seven pairs of animals per dose level of apomorphine. Numbers in columns indicate the number of pairs that exhibited that particular behavior. Stereotypy refers to licking or biting cage wire and circling the cage. Rearing refers to aggressive posturing with no actual fighting. Boxing refers to aggressive posturing with whiskers intermeshed and paws touching. Wrestling refers to a lunging type of fighting; one rat holds the other's head down with its paws. Rumping refers to one rat's attacking by swinging its pelvic girdle at the other rat; the attacker usually pins the other rat's head or body to the side of the cage. Vocalization refers to squealing, whining, or teeth chattering. Tail holding refers to one rat's holding the other rat's tail in its mouth as they circle the cage.

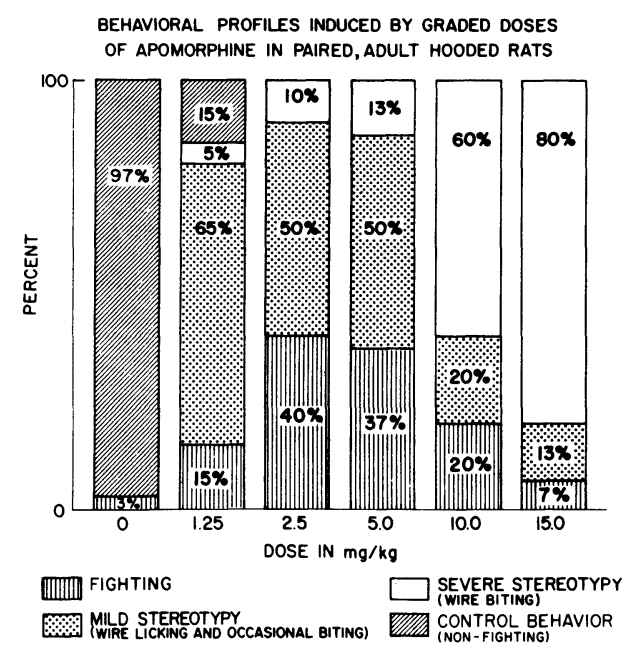

Figure 2. Behavioral profiles induced by graded doses of apomorphine in paired adult hooded rats. Note the inverted $U$-shaped fighting response and the progressive induction of severe stereotypy as dose level is increased. 
are compared with respect to percent of time spent engaged in such behaviors. At the lowest dose $(1.25 \mathrm{mg} /$ $\mathrm{kg}$ ) control, behaviors are nearly gone; at all subsequent doses, such behaviors are totally absent. Fighting followed an inverted U-shaped function and was progressively replaced by mild to severe stereotypy as dose increased.

\section{DISCUSSION}

The results of this study confirm the previous reports (McKenzie, 1971; Senault, 1970, 1971, 1972, 1973, 1974) that apomorphine induces severe intraspecific aggression in the rat and provides detailed descriptions of both aggressive and nonaggressive behaviors. A clear-cut dose-response relationship for both nonaggressive and aggressive behavior has been demonstrated.

The response topography of the aggressive behavior in this study was similar to the defensive fighting described for the normal untreated animal (Zook \& Adams, 1975). Attacks were well-coordinated and directed at the other animal. Few signs of submissive behavior were seen in any of these animals, including those suffering extensive injuries. These results are at variance with the observations of McKenzie (1971), who reported that dominant and submissive fighting stances were quickly established after the onset of the aggressive response. Animals in the present study adopted defensive stances and engaged in boxing maneuvers. This sequence was not followed, however, by submission of one of the animals, as was reported by McKenzie (1971).

The sequela to sudden sensory stimulation was in some cases an attack, but other attacks occurred in the absence of such stimulation. It is possible that such stimuli were present, but not discernible to the observer. Potentiation by sensory stimulation may account for the effectiveness of the "waking bell" used by Senault (1970) in producing high fighting time.

The dose-response relationship found in the experiment shows an apparent incomfatibility between the aggressive and nonaggressive behavior $\mathrm{pa}^{+}$.terns induced by apomorphine. Stereotypy occurs in two forms: mild stereotypy with low doses, and severe stereotypy with high doses (Sahakian \& Robbins, 1975). The second type of behavior observable in paired rats is that of aggression. The present data indicate that the intensity of stereotyped behavior is linearly dose dependent. However, the curves describing aggressive behavior all show an inverted $U$ shape, with doses at the extremes $(1.25 \mathrm{mg} / \mathrm{kg}, 15 \mathrm{mg} / \mathrm{kg})$ resulting in relatively little fighting and intermediate doses $(2.5,5.0 \mathrm{mg} / \mathrm{kg})$ inducing the highest level of aggression. Thus, at low doses, apomorphine induces mild stereotypy that gives way to fighting as the dosage is increased. At the highest dose levels, aggression is replaced by severe stereotypy. As noted before, previous investigators have described the progression from mild to severe stereotypy with increasing doses, but most of these observations have been made on rats studied individually. The present results indicate that when male rats are paired, an aggressive response intervenes between mild and severe stereotypy.

Apparently, a rather wide range of doses of apomorphine may induce fighting. For example, a study by Thor and Ghiselli (1975) reported high levels of aggression in animals injected intraperitoneally with a $20-\mathrm{mg} / \mathrm{kg}$ dose of apomorphine. In our study, a $15-\mathrm{mg} / \mathrm{kg}$ dose of apomorphine yielded aggressive behavior no different from control. Thor and Ghiselli made their observations on animals placed in an arena in groups of four immediately after injection. It may be that the effective circulating level of apomorphine during their 5-min period was relatively low and perhaps comparable to the lower doses of the present study.

McKenzie (1971) reported that animals rarely fought at doses below $10.0 \mathrm{mg} / \mathrm{kg}$ and never below $5.0 \mathrm{mg} / \mathrm{kg}$ given subcutaneously. In his study, no animals above 84 days of age were tested. Since McKenzie (1971) reported a positive relationship between increasing age and apomorphine-induced aggression, it may be that the animals used in the present experiment (90-110 days old) simply represent the next step in a linear progression. However, McKenzie tested only two pairs of rats at each dose, and the variability commonly seen in apomorphine-induced aggression (13\% nonfighters in the present study and $62 \%$ nonfighters reported in the original Senault, 1970, study) may have affected the outcome. Senault reported a maximum effect at a dose of $1.0 \mathrm{mg} / \mathrm{kg}$ given intravenously using a logarithmic progression of doses ranging from $.01 \mathrm{mg} / \mathrm{kg}$ to $10.0 \mathrm{mg} / \mathrm{kg}$ (Senault, 1970). No animals were tested at doses between 1.0 and $10.0 \mathrm{mg} / \mathrm{kg}$. The failure to test at intermediate doses and the use of auditory stimulation may account for the discrepancies between Senault's results and those of the present study.

Aggression was by far the most striking component of the apomorphine-treated animal's behavioral repertoire. Apparently, apomorphine potentiates aggression, resulting in the abolition of other social responses. The ultimate importance of this finding is unclear, but it leaves room for speculation concerning the possible prepotency of aggressive behavior and/or the specific neural pathways involved. The fact that apomorphine-induced aggression is selectively abolished by amygdaloid lesions suggests that these results may be attributable to dopaminergic stimulation of the amygdala (Senault, 1973), although apomorphineinduced aggression also depends upon the integrity of cholinergic (Senault, 1970) and adrenergic (Senault, 1973) systems. Stereotypy, on the other hand, is thought to be mediated by dopaminergic mechanisms within the corpus striatum (Senault, 1973). Obviously, further research is needed on both the behavioral aspects and neural mechanisms involved in apomorphine treatment. Nevertheless, the present study demonstrates that apomorphine induces qualitatively different behaviors at different doses.

\section{REFERENCES}

Gotsick, J. E., Drew, W. G., \& Proctor, D. L. Apomorphineinduced aggression: An evaluation of possible sensitizing factors in the rat. Pharmacology, 1975, 13, 385-390.

McKenzie, G. M. Apomorphine-induced aggression in the rat. Brain Research, 1971, 34, 323-330.

Sahakian, B. J., \& Robrins, T. W. Potentiation of locomotor activity and modification of stereotypy by starvation in aponorphine treated rats. Neuropharmacology, 1975, 14, 251-257.

Senault, B. Comportement d'agressivité intraspecifique induit par l'apomorphine chez le rat. Psychopharmacologia (Berlin), 1970, 18, 271-278.

Senault, B. Influence de l'isolement sur le comportement d'agressivité intraspecifique induit par l'apomorphine chez le rat. Psychopharmacologia (Berlin), 1971, 20, 389-394.

Senault, B. Influence de la surrenalectomie de l'hypophysectomie, de las thyroidectomie, de la castration ainsi que de la testosterone sur le comportement d'agressivité intraspecifique induit par l'apomorphine chez le rat. Psychopharmacologia (Berlin), 1972, 24, 476-484.

Senault, B. Effets de lesions du septum, de l'amygdale, du striatum, de la substantia nigra et de l'ablation des bulbes olfactifs sur le comportement d'agressivité intraspecifique induit par l'apomorphine chez le rat. Psychopharmacologia (Berlin), 1973, 28, 13-25.

Senault, B. Amines cérébrales et comportement d'agressivite intraspecifique induit par l'apomorphine chez le rat. Psychopharmacologia (Berlin), 1974, 34, 143-154.

SEWARD, J. P. Aggressive behavior in the rat. I. General characteristics; age and sex differences. Journal of Comparative Psychology, 1945, 38, 175-198.

Thor, D. H., \& GHiselli, W. B. Suppression of mouse killing and apomorphine induced social aggression in rats by local anesthesia of the mystacial vibrassae. Journal of Comparative and Physiological Psychology, 1975, 88, 40-46.

Zоок, J. M., \& Adams, D. B. Competitive fighting in the rat. Journal of Comparative and Physiological Psychology, 1975, 88, 418-423.

(Received for publication July 17, 1980.) 